\title{
Design of New Submerged Ozone Generator
}

\author{
Hongxia Wang* , Yun Long, and Yuying Ji \\ School of mechanical engineering, Hubei University of Automotive Technology ,Hubei Shiyan ,442002, China
}

\begin{abstract}
In order to meet the demand of adjustable ozone concentration and reduce energy consumption, a new submerged ozone generator was designed. The nozzle, reaction chamber and electrode plate were studied and optimized. The mechanical structure design of the device was completed. The electrical circuit model was built by Matlab/Simulink, the design of power system is completed. The results show that the generation and reaction of ozone are completed in the treated water to effectively reduce the temperature of the reaction chamber. Moreover, by adjusting the parameters of discharge gap and cathode plate area, ozone can be adjusted as requirement to meet the purification requirements of different water bodies. It provides the technical information and data support for further experimental research and application of the new submerged ozone generator.
\end{abstract}

\section{Introduction}

In water treatment, ozone has strong oxidizing properties. Compared with chlorine, ozone is more toxic to viruses, especially some stubborn gastrointestinal bacteria and algae. Ozone is gradually replacing chloride and becoming the main force for purifying water bodies. People's demand for ozone is increasing. So many scholars have conducted extensive research on the structure and characteristics of ozone generating devices. Wei Linsheng ${ }^{[1]}$ conducted an experimental study on ozone generated by high-frequency and high-voltage dielectric barrier discharge and sorted out the chemical reaction mechanism of low-temperature plasma under various conditions. Lai Shiqiang ${ }^{[2]}$ and others used electro-hydraulic pulse technology to control algae in water bodies, and analyzed the structure of the generating device that directly generates ozone in the water body and the main factors that affect the ozone yield. However, moisture affects the breakdown properties of gas molecules and the morphological distribution of micro-discharges in the working air gap ${ }^{[1]}$. Qian Zhengguo [3] designed a high-frequency, high-efficiency DBD ozone generating power supply and studied its characteristics under different control strategies. Other scholars ${ }^{[4-8]}$ have also carried out related research on the characteristics and influencing factors of ozone generators. This study combined with the research results of others and the factors that affect the ozone yield, aiming at the problems of poor heat dissipation of the existing ozone purification system, low ozone output and poor versatility, it is planned to design a new type of submerged ozone generating device, complete the mechanical structure design of the device, design and simulate the power supply control system. In this way, the electrical parameters in the loop are optimized to determine the reasonable configuration of the equipment parameters of the entire set of devices. This paper provides technical data and data support for the further development of the experimental research and application of the device in the later period.

\section{Mechanical structure design of submerged ozone generator}

\section{1 working principle}

According to previous theories and experimental studies, there are many factors affecting ozone productivity ${ }^{[1-8]}$, including air humidity, electrode structure and materials, air gap, voltage amplitude, discharge frequency, gas flow and cavity pressure and temperature. A new type of submerged ozone generating device was designed in combination with the influence of main factors. The device includes a cabinet, an ozone generator, a water circulation system and a power supply system. Figure 1 is a mechanical structure of submerged ozone generator.

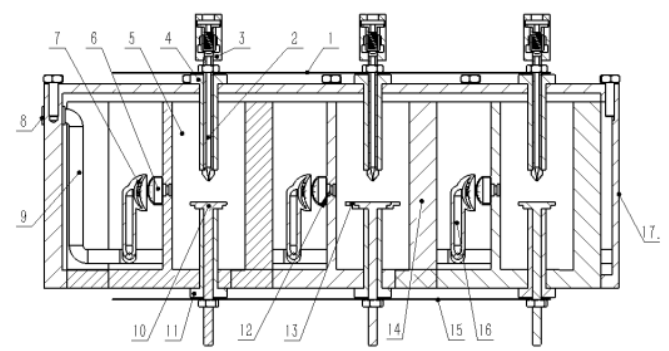

1、Positive patch board 2、Electrode nozzle 3、 Check valve 4、Positive insulation sealed tube

5、Ozone reaction chamber 6、Funnel-shaped jet 7、Funnel-shaped 
sprinkler 8、water inlet

9、Intake pipe 10、 Electrode plate 11、Negative insulation sealed tube 12、 Check valve 13、Variable area electrode plate

14、Reaction chamber shell 15、 Negative patch board 16、Manifold 17、 shell 18、Outlet

Fig. 1. Mechanical structure of submerged ozone generator.

The working principle of this device is as follows, the dried air is sent to the check valve, then it enters the closed generation chamber through the anode nozzle, the high-frequency high-voltage alternating current is provided to the ozone generator electrode by the power supply system, which generates pulse current to breakdown the air, and ionization generates ozone. Ozone is sprayed through the fan-shaped nozzle through the check valve and mixed with the water body, and the ozone and water are mixed through the water circulation system to purify the water body and take away the heat generated by the ozone generation outdoor wall.

\subsection{Mechanical design}

The cabinet is designed as a modular cabinet, and the number of splicing reaction chambers can be selected according to the amount of wastewater treatment. The outlet of ozone and the outlet of water to be treated are designed as fan-shaped nozzles, which can increase the contact area of the treated water and ozone and improve the utilization rate of ozone.

In the design of the ozone generating chamber, the electrode pair is installed inside a closed reaction chamber, the purpose is to isolate the ozone generating chamber and the reaction chamber of ozone and water, effectively reducing the adverse effects of humidity on ozone, thereby increasing ozone yield. At the same time, the reaction chamber of the ozone generating device is submerged in the treated water, and the heat generated by the ionization takes away the heat of the reaction chamber under the action of the water pump through the outer wall of the ozone generating wall, thereby reducing the temperature of the reaction chamber and increasing the ozone generation rate.

In the design of the electrode pair, the guide rod of the anode nozzle is threaded, and the thread is used to adjust the discharge gap spacing, change the ionization rate and ozone output, and meet the requirements of ozone concentration and yield under different working conditions, so as to meet water purification requirements. Because it is corona discharge, coupled with the use of high-frequency high-voltage signals, the size of the cathode plate area plays a vital role in the size of the discharge voltage. The polar plate is designed as a variable polar plate, the area can be adjusted through bolt connection, the ozone concentration can be adjusted, and different sizes of polar plates can be selected according to the working conditions.

\section{Design and simulation of power supply system for submerged ozone generator}

\subsection{Power system design}

Figure 2 is a schematic diagram of the power supply system of the ozone generating device, which is mainly composed of a rectifier filter circuit, an inverter circuit, a high-frequency booster and an ozone generator load. The three-phase alternating current is used as the input voltage, and the three-phase full-bridge uncontrollable rectifier circuit composed of six diodes is connected, and the unidirectional conduction characteristic of the diode is used to change the alternating current into direct current. Through the LC filter circuit, provide a stable output DC power for the inverter bridge; through the inverter bridge, it becomes a square wave AC signal. The high-frequency and high-voltage voltage obtained through the step-up transformer is sent to the anode nozzle and the cathode plate respectively to discharge, instantaneously break down the air, and generate a high-frequency pulse current. After the gas is ejected from the anode nozzle, it is ionized by the high-voltage pulse current to generate high temperature and high pressure , strong ultraviolet rays, ozone, cavitation flow, shock waves and a large number of free radicals. The ionized products are ejected from the ozone generating chamber along the jet head and mixed with the water column jetted from the water jet head to complete the purification of the water body.

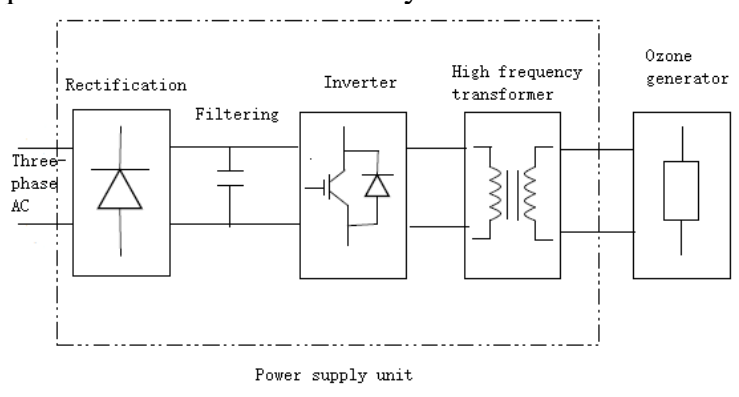

Fig.2. Schematic diagram of power system of ozone generator

\subsection{Power system circuit simulation}

In order to verify the correctness of the calculation results of the power system parameters and to select appropriate electrical parameters to meet the working needs of the ozone generating device, the simulation model of the main circuit of the submerged ozone generating device is established as shown in Figure 3. The parameters of the power control system of the submerged ozone generator are as follows: input three-phase alternating current: $380 \mathrm{~V}, 50 \mathrm{~Hz}$; output working frequency: $4 \mathrm{~K} \sim 5 \mathrm{KHz}$; output AC voltage: $10 \mathrm{KV} \sim 15 \mathrm{KV}$, working efficiency: $80 \%$.

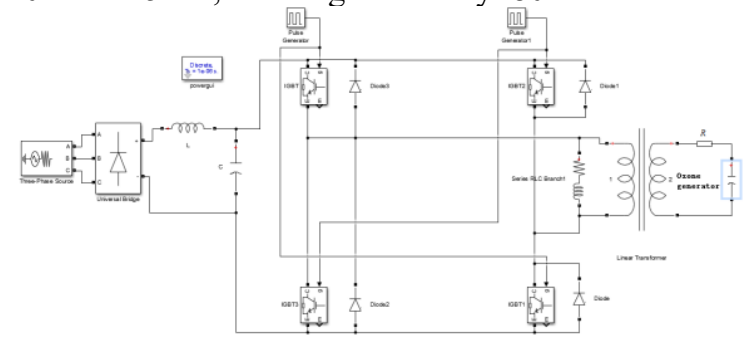


Fig. 3. Simulation model of power system of submerged ozone generator

Using Matlab / Simulink software to simulate and analyze the rectifier filter circuit, IGBT voltage inverter circuit and high frequency boost circuit respectively, the appropriate electrical parameters are determined, and the main circuit simulation study of the power system of the submerged ozone generator is completed. Obtaining the electrical parameters that meet the working requirements as shown in Table 1, the effective value of each important node voltage is shown in Table 2, and the voltage waveform simulation diagram is shown in Figure 4-7:

Table 1. Main electrical parameters of power supply system

\begin{tabular}{cccccc}
\hline $\begin{array}{c}\text { Filter } \\
\text { capacit } \\
\text { or } \\
C(\mu \mathrm{F})\end{array}$ & $\begin{array}{c}\text { Filter } \\
\text { inducta } \\
\text { nce } \\
L(\mathrm{mH})\end{array}$ & $\begin{array}{c}\text { IGBT } \\
\text { drive } \\
\text { frequen } \\
\text { cy } \\
f_{s}(\mathrm{~Hz})\end{array}$ & $\begin{array}{c}\text { IGBT } \\
\text { output } \\
\text { resistan } \\
\text { ce } \\
R(\Omega)\end{array}$ & $\begin{array}{c}\text { IGBT } \\
\text { output } \\
\text { inducta } \\
\text { nce } \\
(\mathrm{mH})\end{array}$ & $\begin{array}{c}\text { Turns } \\
\text { ratio }\end{array}$ \\
\hline 3300 & 1 & 5000 & 10 & 1 & 25 \\
& & & & & \\
\hline
\end{tabular}

Table 2. Important node voltage of power system

\begin{tabular}{|c|c|c|c|c|}
\hline & $\begin{array}{l}\text { Voltage } \\
\text { type }\end{array}$ & $\begin{array}{c}\text { Voltage } \\
\text { value }(\mathrm{V})\end{array}$ & $\begin{array}{c}\text { frequency } \\
(\mathrm{Hz})\end{array}$ & $\begin{array}{c}\text { Correspo } \\
\text { nding } \\
\text { waveform }\end{array}$ \\
\hline $\begin{array}{l}\text { Rectified } \\
\text { voltage }\end{array}$ & $\begin{array}{c}\text { DC / } \\
\text { average } \\
\text { voltage }\end{array}$ & 500 & $\sim$ & Figure 4 \\
\hline $\begin{array}{c}\text { Voltage } \\
\text { after } \\
\text { inverter }\end{array}$ & $\begin{array}{c}\text { AC / } \\
\text { voltage } \\
\text { effective } \\
\text { value }\end{array}$ & 498 & 5000 & Figure 5 \\
\hline $\begin{array}{l}\text { Voltage } \\
\text { across the } \\
\text { ozone } \\
\text { generator }\end{array}$ & $\begin{array}{c}\text { AC / } \\
\text { voltage } \\
\text { effective } \\
\text { value }\end{array}$ & 12010 & 5000 & Figure 6 \\
\hline
\end{tabular}

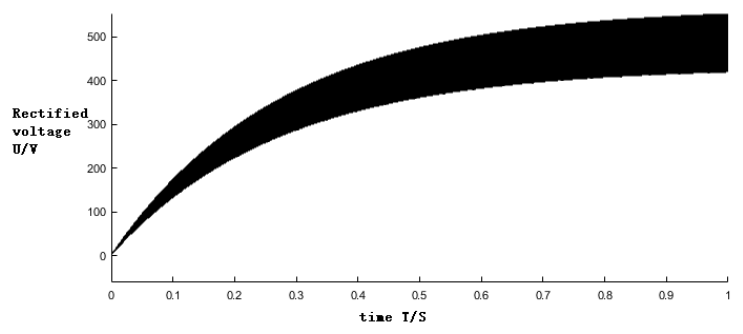

Fig. 4. Voltage waveform after rectification

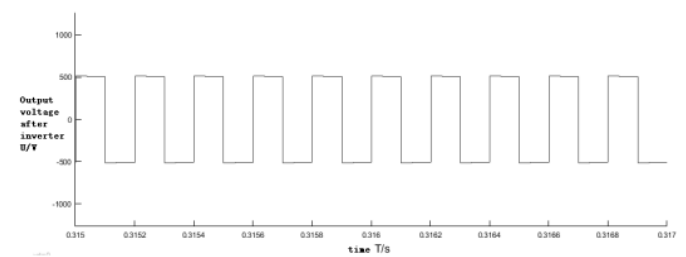

Fig. 5. Stable voltage waveform after inverter

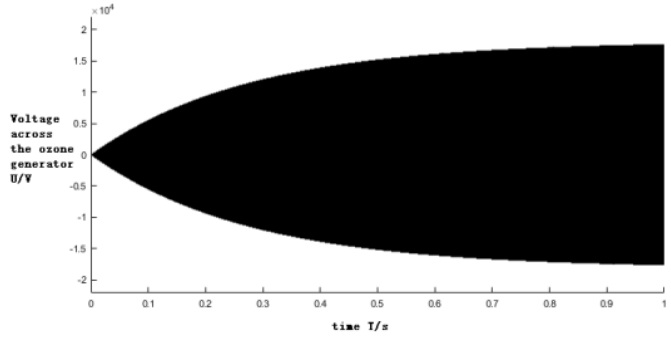

Fig. 6. Voltage waveform of ozone generator

According to the simulation results, the voltage frequency after the inverter meets the frequency required by the plasma ozone generator, so the circuit topology is successful.The circuit parameters and control circuit design are feasible.

\section{Conclusion}

(1) A new type of submerged ozone generator was designed. The electrode pair is installed in the closed reaction chamber, which can reduce the influence of humidity. The generation and reaction of ozone are completed in the treated water body, which can reduce the temperature of the reaction chamber and increase the ozone yield.

(2) Use modular box. The number of reaction chambers is determined according to the amount of water and the degree of pollution; the threaded connection of the anode nozzle guide rod is used to adjust the discharge gap, and the area of the cathode electrode plate is adjusted by bolt connection to meet the purification requirements of different water bodies.

(3) The high-frequency and high-voltage simulations at both ends of the ozone generator are close to the theoretical calculations, which meets the power supply conditions for ozone generation. The design and parameters of the power control system are feasible.

\section{Acknowledgements}

This work was supported by the Hubei Province Education and Science(2018GB030); Innovation Project of Graduate Education (Y2018202); the Natural Science Fund of Hubei Province (2017CFB741); the Foundation of Hubei Ministry of Education (B2016089); the items of educational research of Hubei Automotive Industries Institute (JX201618) and (2019JXXY12).

\section{References}

1. Wei LS. Theoretical and experimental research on ozone generation by gas discharge plasma[D]. Hang'zhou: Zhejiang University, 2008.

2. Lai SQ, Liao ZF. Research on anunderwater ozone generator based on electro-hydraulic power impulse technology $[\mathrm{J}]$. Journal of functional materials, 2011,42(06):1038-1040+1044. 
3. Qian ZG. Control strategy research anddesign of DBD ozone generation[D].Nan'jing:Southeast University, 2018.

4. J.M.Alonso, M.Rico-Secades, E.Corominas. Low-power high-voltage high-frequency power supply for ozone generation[J]. Universidad de Oviedo,DIEECS-Electr6nica, 2002 IEEE, 257-262.

5. Wang HX, Liu Q, Chen Z, et al. Parameters design and characteristic research of an underwater ozone generator $[\mathrm{J}]$. Science Technology and Engineering, 2013, 13(33): 9877-9881.

6. Deng HZ. Ozone yield limit in low temperature plasmas and temperature effect[D]. Nan'chang: Nanchang University, 2019.

7. Abdelaziz A A, Ishijima $T$, Seto $T$, et al. Characterization of surface dielectric barrier discharge influenced by intermediate frequency for ozone production[J]. Plasma Sources Science and Technology, 2016, 25(3): 035012. 